\begin{tabular}{c|c|c} 
Issues in & $\begin{array}{c}\text { Informing Science }+ \\
\text { Information Technology SCEN }\end{array}$ & $\begin{array}{l}\text { An Offial Publication } \\
\text { of the Informing Science Institute } \\
\text { InformingScience.org }\end{array}$ \\
\hline IISTITUTE & IISIT.org
\end{tabular}

Volume 18, 2021

\title{
ZOOMING?! - HIGHER EDUCATION FACULTY Perspectives
}

\begin{tabular}{lll}
\hline Moshe Leiba* & The Academic College of Tel-Aviv & mosheli@mta.ac.il \\
& Yaffo, Tel Aviv, Israel \\
Ruti Gafni & The Academic College of Tel-Aviv \\
& Yaffo, Tel Aviv, Israel & rutigafn@mta.ac.il \\
* Corresponding author &
\end{tabular}

ABSTRACT

Aim/Purpose

The COVID-19 pandemic demanded an immediate and massive adaptation of higher education to distance learning. Teachers had to transform from face-to-face to distance teaching, with insufficient pedagogical and technological knowledge and resources. This study aims to capture higher education faculty experiences in the very early stages of the crisis-prompted transition into synchronous distance education in order to obtain a broader view on the faculty's perspectives (benefits, challenges and insights) on distance teaching through synchronous online environments.

Background Although online teaching and learning have been part of higher education teaching for more than two decades, many instructors found themselves teaching remotely for the first time and facing new and unpredicted challenges.

Methodology This study explored and analyzed an e-mail thread discourse between teachers in a higher education institute, two months after "going online" due to the COVID-19 pandemic. A singular case study was conducted, and a retrospective and snapshot case study approach was used. Data analysis was an iterative exploratory process of going back and forth the empirical material, resulting in the construction of categories, then themes, and finally a conceptual framework was developed.

Contribution The findings contribute the knowledge domain of implementation of immediate and massive online teaching and learning from the faculty perspective.

Findings $\quad$ Two main focal points, students and teachers, were encountered. Three main recurring themes were identified associated with both students and teachers: Convenience, Ethical Issues, and Insights for the future. Two themes were

Accepted by Editor Eli Cohen | Received: February 21, 2021 | Revised: May 3, 2021 |

Accepted: June 1, 2021.

Cite as: Leiba, M. \& Gafni, R. (2021). Zooming?! - Higher education faculty perspectives. Issues in Informing Science and Information Technology, 18, 121-140. https://doi.org/10.28945/4791

(CC BY-NC 4.0) This article is licensed to you under a Creative Commons Attribution-NonCommercial 4.0 International License. When you copy and redistribute this paper in full or in part, you need to provide proper attribution to it to ensure that others can later locate this work (and to ensure that others do not accuse you of plagiarism). You may (and we encourage you to) adapt, remix, transform, and build upon the material for any non-commercial purposes. This license does not permit you to use this material for commercial purposes. 
Recommendations for Practitioners

Recommendations for Researchers

Impact on Society

Future Research identified associated with faculty: Pedagogy and Tools, and Resources. In addition, two themes were identified for students: Attendance and Responses. Each of the themes was decomposed into several aspects.

Higher education institutions and stakeholders should build a campus wide elearning agenda including appropriate infrastructure and professional development for the future.

The study presented a conceptual model based on qualitative case study methodology. The impact and influence of each of the components of the model should be further researched and measured using quantitative methodologies.

Understanding the benefits and challenges of distance learning from the faculty perspectives in order to implement better distance learning strategies.

The impact and influence of each of the components of the model should be further researched and measured using quantitative methodologies.

Keywords cation

\section{INTRODUCTION}

What have been the main talking points among academics as we've adapted to online teaching this year? The logistics of managing Zoom or Teams? Developing curriculum content? Making learning sessions engaging? (Heaton, 2020)

In the last two decades, in parallel with the expansion of high-speed Internet access, online distance teaching has kept expanding to academic systems, mainly in the US, growing faster than they have for the past several years (Seaman et al., 2018). Still, traditional face-to-face teaching accounts for most courses in academic institutions. With the outbreak of the global COVID-19 pandemic, many people found themselves in lockdowns, working and studying from home (MacKenzie, 2020). At the highest, on April 2nd, 2020, schools and higher education institutions were closed in 172 countries, affecting 1,484,712,787 learners, which constitute $84.8 \%$ of total enrolled learners in the world who were out of the educational system (UNESCO, 2020). Distance teaching has become the main method of teaching in most schools and higher education institutions around the world. The COVID-19 pandemic demanded an immediate and massive adaptation, of all teachers and classes, to distance learning to maintain educational routines and continuity. The initial concern was not about whether online teaching and learning methods can provide quality education, but rather how academic institutions will be able to adopt online teaching and learning in such a massive manner. Most teachers had to transform from face-to-face teaching to distance teaching in a very short time without training, with insufficient pedagogical and technological knowledge and resources, and with little preparation. In addition, also most of the students were not experienced in distance learning. The International Association of Universities (IAU) carried out a global survey on the impact of COVID 19 on universities and other higher education institutions in 109 countries (Marinoni et al., 2020) and determined that at almost all higher education institutions (424 replied to the survey), COVID-19 affected teaching and learning, with two-thirds of them reporting that classroom teaching has been replaced by distance teaching and learning. The shift from face-to-face to distance teaching did not come without challenges, the main ones being access to technical infrastructure, competences and pedagogies for distance learning, and the requirements of specific fields of study. Early research (Dietrich et al., 2020) suggests that teachers recognize that they have learned more about distance education in the early two months of the pandemic than in the past ten years, and this was the result of their constant commitment and dedication to education during this crisis. Now that the initial shock has passed, it is 
a good time to reconsider how we might better invest time and resources in course design (Rapanta et al., 2020).

Two months into the transformation, an e-mail discourse started between The Academic College of Tel-Aviv Yaffo's faculty, raising questions, and presenting insights summarizing their experience in teaching from a distance, specifically in a synchronous medium. This study explored and analyzed the discourse between the faculty to obtain a broader view on the factors associated with the sudden change in teaching methodology under crisis conditions, such as those caused by COVID-19.

\section{THEORETICAL FRAMEWORK}

Online teaching and learning have been part of higher education teaching for more than two decades (Singh \& Thurman, 2019). Yet, faculty are reluctant to embrace different forms of online teaching, due to fear of change, concerns about the reliability of technology, concerns regarding student outcomes in online learning environments, workload issues, and other factors (Betts \& Heaston, 2014; Bolliger \& Wasilik, 2009; McQuiggan, 2012).

\section{ONLINE TEACHING AND LEARNING}

Over the years, various models of e-learning were developed, and it can be described as a continuum (Figure 1) from the integration of technology in the learning process (Enhanced mode), through Blended courses (such as a combination of face-to-face and online learning), to fully online courses (part of the regular curricula, extra accreditation and open to the general public). On the one end of the scale, e-learning enhances face-to-face teaching, such as online pedagogical tools, online learning material, and administrative information. When courses include online discussions, assessment, and assignments, the proportion of web-based activities increases up to a point where classroom activities decrease, and on the extreme, e-learning is fully online (Garrison \& Kanuka, 2004; Soffer \& Cohen, 2019).

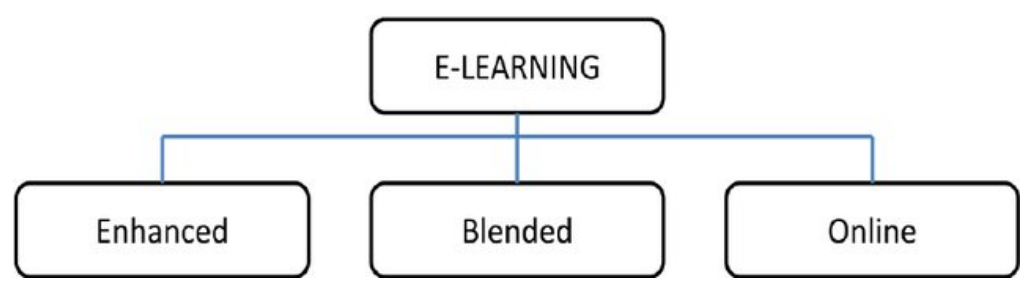

Figure 1. A continuum of e-learning (Garrison \& Kanuka, 2004)

There is a variety of definitions of online teaching and learning (e.g., Kozma, 2000; Kurtz et al., 2006). A more recent and comprehensive definition of online learning is "learning experiences in synchronous or asynchronous environments using different devices (e.g., mobile phones, laptops, etc.) with internet access. In these environments, students can be anywhere (independent) to learn and interact with instructors and other students" (Singh \& Thurman, 2019).

Several arguments are associated with online teaching and learning. Accessibility, affordability, flexibility, innovative pedagogy, and policy are some of the arguments related to online pedagogy. It is considered to be a relatively cheaper mode of education in terms of the lower cost of transportation, accommodation, and the overall cost of institution-based learning. Flexibility is another interesting aspect of online learning; a learner can schedule or plan their time for completion of courses available online. Combining face-to-face lectures with technology gives rise to blended learning and flipped classrooms; this type of learning environment can increase the learning potential of the students. Students can learn anytime and anywhere, thereby developing new skills in the process leading to lifelong learning (Dhawan, 2020; Gafni et al., 2011). Reeves and Reeves (2012) propose five essential strategies in the design and online teaching process: (1) observing the grounds of efficient teaching- 
learning; (2) maximizing the synchronization of essential elements of the learning environment (objectives, content, training model, tasks, roles of the participants, and assessment); (3) maintaining cognitive, social, and teaching presence; (4) gradual introduction of new technologies; (5)formative and continuous assessment of the formation experience to improve it.

\section{ONLINE SYNCHRONOUS TEACHING AND LEARNING}

Online teaching can be implemented using asynchronous or synchronous methods or a combination of both. A synchronous learning environment is based on live lectures and activities with real-time interactions between instructors and students participating from different localities with the possibility of instant feedback. Synchronous distance learning requires teachers and students to work together, at a specific time frame, and focuses on reconstructing the traditional in-class learning environment over the web (Yang \& Liu, 2007). In a synchronous learning environment, learners can raise a question at any time and teachers can respond promptly to reinforce or extend students' learning. In addition, synchronous distance learning provides opportunities for collaborative learning, group discussion, peer tutoring. and brainstorming. A synchronous learning environment enables both visual learning and verbal learning, as instructors can ask learners to answer particular questions with text, graphics, or audio.

Students' increasing use of 'instant' media and access to the Internet have changed some of their expectations for course delivery from face-to-face to online (Sanford et al., 2017). One of the key elements of synchronous learning in the "Culture of impatience and instant gratification" is the ability to provide opportunities for immediate social interaction (McBrien et al., 2009). Such online platforms are needed where discussions with students can be done to keep classes organic, there is the possibility of watching already recorded lectures, and instant feedback from students can be achieved and assignments can be taken (Basilaia \& Kvavadze, 2020).

\section{FACULTY AND ONLINE TEACHING}

Online teaching is a complex task that requires commitment from faculty and can be time consuming and demanding. Online teaching has become an expectation and an element of instructors' regular teaching loads at many higher education institutions.

Faculty involvement considered to be a key factor for a successful and sustainable educational change (Emo, 2015), yet most faculty have no formal education training, relying primarily on their experience as a student and face-to-face instructor. With the continuous change with online technologies, readiness to teach online may be in a state of flux (Varvel, 2007). Faculty readiness to teach online can be defined as a state of faculty preparation for online teaching. Key aspects of faculty readiness are faculty attitudes on the importance of online teaching competency and their perception of their ability to confidently teach online. These aspects play a major role in how faculty approach online teaching goals, tasks, and challenges (Martin et al., 2019). Wray et al. (2008) postulate that faculty member's past teaching experience serves as foundation to teaching online. However, online teaching is different from teaching face-to-face, and the online faculty member's role is different from that of a faculty member teaching in the classroom (Ko \& Rossen, 2017). Clay (1999) found that factors that influence faculty's positive attitudes toward teaching online are prior experience teaching online, availability of online courseware, improved training and facilities, feedback from students, and flexibility of time and teaching schedules. Shea's (2007) study showed that the number of times faculty had taught online was an important consideration in how motivated faculty are in the online modality; with more experience in the online teaching, self-confidence levels increase. Less experienced faculty report that they struggle to communicate because of the absence of face-to-face interaction, are unfamiliar with effective online pedagogy, lack the opportunity to observe online teaching before engaging in it, lack the opportunity to experiment with the technologies of online teaching, and have inadequate time to learn about online teaching. Faculty with little to no online teaching experience have lower percep- 
tions of their ability in online teaching than those with more than five years' experience. It is not surprising that faculty with more teaching experience online have greater perceived levels of proficiency to perform pedagogical competencies (Carril et al., 2013; Martin et al., 2019). Moreover, faculty who taught both in asynchronous and synchronous modalities had higher self-efficacy for course design, and faculty who taught asynchronous had higher self-efficacy for time management compared to faculty who taught face to face (Vang et al., 2020).

There are three elements important to faculty who teach online courses: students, the instructor, and the institution. These three factors are important in the measurement of perceived faculty satisfaction. Bolliger and Wasilik (2009) found that the student factor is the most important factor influencing satisfaction of online faculty and concluded that many online instructors are student centered.

Regarding the transformation and adjustment of face-to-face content and methods to online ones, the faculty are responsible in doing so. The task of generating new materials or adjusting the materials from face-to-face classes to an online setting can be very challenging (Li \& Irby, 2008). Content cannot simply be copied from a face-to-face to an online setting. However, instructors may not be willing to change their teaching strategies when transitioning from a face-to-face to an online course (Barrett, 2010). Often proper training and support has not been provided to faculty who are transitioning a course content from face-to-face to online settings (Kyei-Blankson \& Keengwe, 2011). In addition to a lack of training and support, instructors also perceive a lack of incentives in designing and delivering online courses (Allen \& Seaman, 2010). Offering appropriate incentives increases an instructor's willingness to design and deliver an online course (Hoyt \& Oviatt, 2013).

\section{ONLINE SYNCHRONOUS TEACHING AND LEARNING DURING COVID-19}

Due to the sudden change caused by the COVID-19 and the need to transfer teaching from face-toface to online, technologic issues, for example having a camera, and knowing how to use it, were almost resolved. However, different of barriers still exist, like low internet bandwidth, which hindrances the flow of the video, or the preferences of some individuals to connect visually anonymously. Tareen and Haand (2020) found some challenges faced by both faculty and students in integrating online learning during COVID-19: (1) students prefer classroom learning situation (face-toface) compared to online learning, (2) unclear instructions from the lecturers, (3) hard to have group interaction, (4) students do not know what criteria will be assessed, (5) students need assistance from lecturer, (6) difficult to retain information, (7) less students' participation, and finally (8) single-student domination.

Many instructors found themselves teaching remotely for the first time and facing new challenges, for example, not being able to see students during synchronous lessons held via the internet, because students do not have their cameras turned on (Castelli \& Sarvary, 2021; Reich et al., 2020). The opportunity of keeping the camera off in video conference mode, yet still being able to attend and interact in course content with teachers in real time, seems to have a lot of attraction to the students (Greener, 2021). Meeter et al. (2020) found that in times of social distancing, as forced during the pandemic of COVID-19, there is a drop in motivation because of lack of social interactions (social integration, online interaction, camera use) and a stronger reliance on self-regulated learning (home facilities and procrastination). In their study, the students appreciated online education less than they did traditional face-to-face classes, felt less motivated and reported spending fewer hours on their studies. Moorhouse (2020) found that the online distance classes are more teacher-centered than face-to-face sessions, and group and whole-class discussions are characterized by longer silences and shorter student responses, which are harder because of the students turning their cameras off due to privacy concerns. In the research of Castelli and Sarvary (2021), they reported they did not enforce turning on cameras during class but encouraged them to do so. However, as the semester advanced, there was a lower than desired camera use that diminished the educational experience and the teachers felt like they were talking to themselves when students' cameras were closed. The most frequent 
reported reasons to turn cameras off were being concerned about their environment: (1) other people in the background or (2) embarrassed of their home environment (Castelli \& Sarvary, 2021; Neuwirth et al., 2020). Other, not frequent reasons reported are related to student's behavior: (3) personal appearance and not being properly dressed (pajamas, hair, etc.), (4) not wanting to be seen walking away from the computer, (5) not paying attention or (6) doing other things while at the computer (Castelli \& Sarvary, 2021; Neuwirth et al., 2020). Only a very small number of students reported technical reasons as (7) cameras not working, (8) lack of personal equipment (camera, headphones) or (9) having a weak internet connection with poor network speed (Krystalli, 2020; Neuwirth et al., 2020).

\section{THE STUDY}

The first lockdown occurred in the beginning of the second semester, on March 15th (semester started on March $8^{\text {th }}, 2020$ and ended on June $26^{\text {th }}$, 2020) and forced the faculty members to adopt different pedagogical strategies in synchronous distance teaching to ensure the continuity and the content of the teaching program without loss of quality. This study focuses on an e-mail thread generated two months into the semester involving faculty from several disciplines in The Academic College of Tel-Aviv Yaffo, a higher education institution in Israel.

This study aims to capture higher education faculty experiences in the very early stages of the crisisprompted transition into synchronous distance education. By investigating the faculty's faced challenges, we envision that the study may support stakeholders in making informed decisions to develop and aid the transition into distance education in the presence and future.

\section{RESEARCH METHODS}

To examine the adaption of higher education faculty to online teaching and to gain a better understanding of the faculty's perceptions, attitudes, and convictions about distance learning during early stages of COVID-19 pandemic, we employed a qualitative case study methodology. The methodology, according to Stake (1995), is a "study of the particularity and complexity of a single case, coming to understand its activity within important circumstances" (p. xi). The characteristics of a case study are the following: Holistic (considering the interrelationship between the phenomenon and its contexts); Empirical (basing the study on their observations in the field); Interpretive (resting upon their intuition and see research basically as a researcher-subject interaction); and Emphatic (reflecting the vicarious experiences of the subjects in an emic perspective) (Yazan, 2015). Yin (2014) offers a more detailed and technical definition of case studies as an empirical inquiry that investigates a contemporary phenomenon within its real-life context, especially when the boundaries between phenomenon and context are not evident.

For this exploratory study, we conducted a singular case study and use a retrospective and snapshot case study approach (Thomas, 2011). It involves the collection of data relating to a past phenomenon in one particular period of time, such as a current event. Discourse analysis is the study of social life, understood through analysis of language in its widest sense (including face-to-face talk, non-verbal interaction, images, symbols, and documents) (Potter \& Wetherell, 1987). Discourse analysis was performed on the e-mail thread that was obtained from the discussion held by the faculty members regarding their insights from the sudden change.

\section{RESEARCH QUESTION}

This study explores how higher education faculty have adapted to online teaching during early stages of COVID-19 higher education lockdown. One overarching research question guided this study: What are the faculty's perspectives (benefits, challenges, and insights) on distance teaching through synchronous online environments? 


\section{CASE DESCRIPTION AND DATA COLLECTION}

We collected our data in a higher education institution located in a central city in Israel. The institution's e-learning usage was mainly to enhance face-to-face teaching, such as online pedagogical tools, online learning material, and administrative information (Enhanced mode) with a very small number of Blended courses (as a combination of face-to-face and online learning in the form of recorded video lessons) (Garrison \& Kanuka, 2004). The main e-learning tool used was MOODLE LMS.

This study is based on one e-mail thread started 14th of May 2020 and ended $18^{\text {th }}$ of May 2020. The thread started with a 299-word spontaneous e-mail sent by a computer science tenured full professor faculty member titled "Thoughts on Online Teaching" who wrote: "For a change, an e-mail that relates to teaching. I wanted to share with you my experiences from teaching almost two months in Zoom and hear what you think..." (e-mail 1, authors' translation). The e-mail described her experience teaching via synchronous teaching environment $(\mathrm{ZOOM})$ and invited the rest of the faculty members to describe their experiences and thoughts after two months of ZOOM teaching. The tread consisted of 39 e-mail messages from 35 faculty members (out of 110 faculty members at tenure track campus wide), who decided to respond to the initial e-mail (51\% Females and 49\% Males, from three main domains: Humanities (57\%), Computer Science (34\%) and Life Sciences (9\%) (Table 1)).

Table 1. Study Participants

\begin{tabular}{|c|l|c|c|}
\cline { 2 - 4 } \multicolumn{1}{c|}{} & & N & Percent \\
\hline Participants & & 35 & $100 \%$ \\
\hline \multirow{3}{*}{ Gender } & Male & 17 & $49 \%$ \\
\cline { 2 - 4 } & Female & 18 & $51 \%$ \\
\hline \multirow{3}{*}{ Domains } & Humanities & 20 & $57 \%$ \\
\cline { 2 - 4 } & Computer Science & 12 & $34 \%$ \\
\cline { 2 - 4 } & Life Sciences & 3 & $9 \%$ \\
\hline
\end{tabular}

The quotes in this study are translations of the original e-mail excerpts. We have stayed as close as possible to the original expressions and idiom. To secure anonymity and confidentiality, we have anonymized our respondents using only the e-mail location in the thread.

\section{DATA ANALYSIS}

Our data analysis was an iterative exploratory process of going back and forth through our empirical material. We used word and spreadsheet processing software (Microsoft Word ${ }^{\circledR}$ and Excel ${ }^{\circledR}$ ) to code, categorize, and identify themes in our empirical material. We first coded our data in terms of content, using codes derived from the exploratory analysis. We developed a coding frame derived from the data itself that captures the analytically significant features of the data. Initially, the coding frame included a list of codes, which was organized according to higher-order code categories, accompanied by code definitions. The coding frame constitutes the analytic instrument with which the raw data was then reduced, classified, and synthesized into a conceptual framework (Gaskell, 2000).

Each step of the coding method was done by one researcher and then was discussed with the second researcher until arriving to an agreement in a joint coding session (a consensus approach), changing their roles from step to step. This was done in order to maintain continuous dialogue between researchers and consistency of the coding (Walther et al., 2013) and to establish inter-rater reliability (IRR) to ensure the trustworthiness of the study (Miles \& Huberman, 1994). This resulted in the construction of categories, then to themes ending in a conceptual framework. 
We utilized Bolliger and Wasilik's (2009) framework as a base for the conceptual framework which consists of two main elements that are important to faculty who teach online courses: the students and the instructor.

\section{RESULTS}

Among the faculty participating in the e-mail thread, all 35 transferred from face-to-face teaching to synchronous online teaching using ZOOM environment (https://zoom.us/), during the COVID-19 pandemic lockdown. Similar to Bolliger and Wasilik (2009), we identified two main focal points in the faculty discourse: the students and the instructor (faculty member). According to this framework, we identified seven main recuring themes regarding the experience of teaching in the first two months of the higher education lockdown associated with both faculty and students (sharing three themes including insights for the future). The conceptual framework based on the themes identified is presented below (Figure 2).

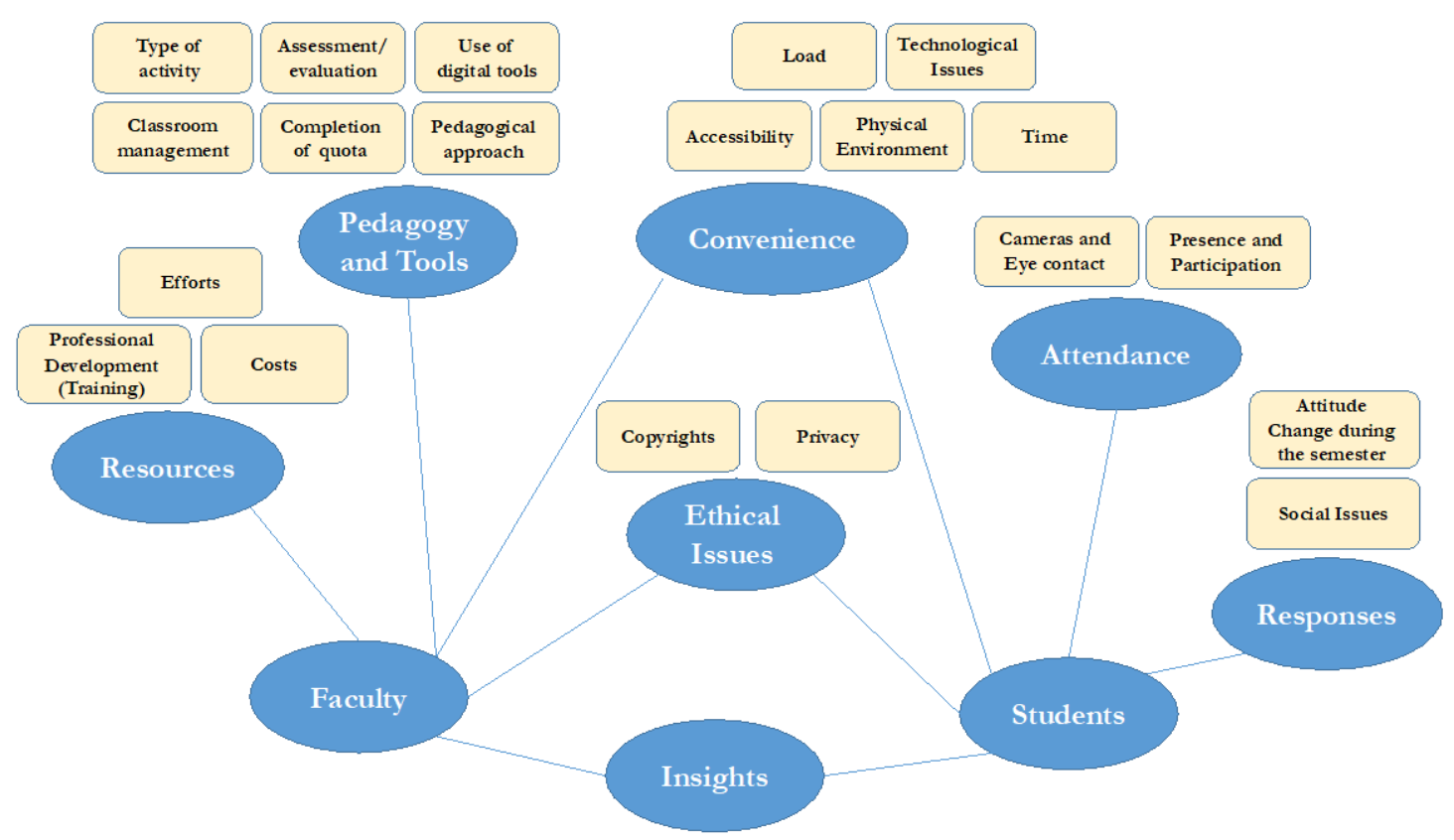

Figure 2. The conceptual framework

The first section relates to the factors associated with faculty, the second one presents the factors associated with faculty and students, and the third one with factors associated with students.

\section{FACTORS ASSOCIATED WITH FACULTY}

The content analysis revealed four main recuring themes associated with the faculty: Pedagogy and Tools, Resources, Ethical issues, and Convenience.

\section{Pedagogy and tools}

Pedagogy is an important aspect of teaching and learning in general and online learning in particular. Faculty work intensively to adapt their planned learning activities to fit distance education. The analysis revealed six aspects: Pedagogical approach, Assessment/evaluation, Use of digital tools, Type of activity, Completion of quota (curriculum wise), and Classroom management. As can be expected, pedagogical approach and use of digital tools were the most discussed in this theme with 18 and 13 mentions respectively. 
As one faculty member wrote: "What we are doing right now is not online teaching but (most of the time and certainly in large courses) duplicating a traditional course through zooming. It is a format that combines the less successful aspects of traditional teaching and of online teaching" (e-mail 34, authors' translation).

Ten out of eighteen mentions were negative, i.e., refer to face-to-face teaching as a better pedagogy enabler than online learning and particularly a synchronous one, not being able to apply advanced pedagogical methods in online teaching. "All this does not happen while using room: ... I started using quizzes embedded in the classroom [in face-to-face teaching]. About a quarter of an hour of theory and then a quizor or two from which I get feedback. from the students regarding the level of understanding, and they also understand where the difficulties are when facing a new topic. In this time frame, students discuss, try to resolve in groups, the classroom is starting to get noisy and while they are working, I spot students who are not trying at all (for their own reasons), I reach out to them and try to help them start..." (e-mail 35, authors' translation).

To the contrary, eight mentions were positive and emphasized the pedagogical advantages in online teaching and the need to adapt to more innovative methods. "The teaching-learning-evaluation approaches such as rotation, flipped classroom, PBL, etc. combined with various digital tools allow for what some of you mentioned - the buman interaction that give each student the possibility to adapt at the appropriate pace, level and scaffolding. Is it possible that students prefer a frontal lecture because they do not have to strain and participate in their learning process? (A question that bothers me a lot)" (e-mail 11, authors' translation).

From the content analysis, we noticed that there are many misconceptions regarding online teaching. For example, the options to conduct a dialogue in the online medium: "So maybe it's a bit of a museum exbibit to teach as same as was thought two hundred years ago (with the obvious changes of presentations and so on). But I came to the conclusion that there is notbing like the old method where the lecturer looks at students in the eyes and conducts a lively dialogue with them" (e-mail 1, authors' translation). Or, the option to practice in small groups and even use better personalization in online teaching: "...the dynamics in the classroom, the expressions across the students [faces] that allow me to navigate the pace of the lesson, the personal attitude, answering questions that arise in the class (unfortunately not heard in online classes), the ability to practice in class and move around students to give an individual answer (again, in zoom it's not possible) and above all, the possibility of seeing who I teach and not feel like I'm talking to a wall/ computer screen/ 70 faceless students" (e-mail 13, authors' translation).

It is interesting to see that when discussing the issue of assessment/evaluation all 5 mentions were negative. All mentions focused on the lack of ability of the faculty to assess the understanding of the students online: "In the classroom] you can see the students, see the eyes and the movement of the body, if it is understood or if further explanations are needed. This is the best feedback" (e-mail 39, authors' translation). Or even the impossible nature to evaluate the active involvement: "the evaluation of the course, is also based on their [the students] active involvement in the lesson - an element that is almost impossible to assess in a room instruction" (e-mail 21, authors' translation).

Regarding the use of digital tools aspect, nine out of thirteen mentions were positive. The tools usually referred to the tools embedded in the ZOOM synchronous environment rather than more sophisticated ones: "The ability to manage the class, as a lecturer, is better and I was able to 'convey' the [learning] material using [digital] tools embedded in the environment and that's even an advantage over the [physical] classroom" (e-mail 16, authors' translation). Most of the faculty used the digital tools as a more technological aid rather than a pedagogical one: "It is very convenient to add additional illustrations/scribbles/examples to the presentations that I usually use in class according to the students' questions. I even became an expert in drawing and writing with the mouse on top of the presentation" (e-mail 1, authors' translation).

Faculty referred in the thread to which activity they think ZOOM (synchronous teaching) is most suited for, mainly the size of class (students wise) and kind of course. We categorized these statements as "Type of activity". The ten statements made by the faculty referenced to several types of activities: small size course, exercise, one-on-one sessions (e.g., mentoring), guest lectures and, as a supplementary tool for an existing face-to-face class. When examining the six statements made about the curriculum, the main concern ( 5 out of 6 ) was the completion of the curricula quota (i.e., the 
teaching materials): "At least, for me the pace is also slower than in face-to-face teaching" (e-mail 3, authors" translation).

Three out of the nine statements mentioning issues relating to classroom management, were positive regarding aspects of noise reduction, "and the lessons start on time, its quieter and there is no talking." (email 1, authors' translation), but that came with the negative aspect of less participation in discussions, "The zoom deepens gaps between students who participate and those who disappear" (e-mail 23, authors' translation).

\section{Resources}

The faculty experience during the first two months of transferring from face-to-face teaching to online synchronous one raised the issue of the resources needed for such a transformation. Three main aspects were identified: efforts, costs (and savings), and professional development (training).

The efforts aspect raised mainly related to the aspects of time needed for the faculty to invest in such a transformation. There were neutral statements as:

"Teaching in front of a class requires a different effort from teaching a zoom class or any virtual class. So I think it's interesting to delve into the question of effort while understanding that the answer to it will often be subjective." (e-mail 5, authors' translation)

However, most of the statements were negative (three):

"In one of the courses I teach... I developed a program [code] to allow the students to practice at home at any given time. It was a success. It took me two weeks, and I'm not the slowest programmer I know." (e-mail 38, authors' translation)

Corresponding with the statements regarding the efforts (from the faculty), two faculty members referred to the costs needed for the institution to transform the teaching methodologies by allocation of more funds:

"Last year when I proposed the college to turn my course into a self-directed course rather than face-to-face, which required more teaching hours, I was denied for budgetary reasons, so if an additional two hours is a problem to develop and deliver an innovative course, I do not really see how will [the institution] approve [budget wise] to re-design courses." (e-mail 33, authors' translation)

Others (also two), mentioned that there are considerable savings too (travel expenses): "enormous savings in gas and petrol" (e-mail 4, authors' translation).

From the professional development (training) aspect, only one explicit mention was made: "I have participated, in the past, in training courses on online teaching tools (through this institution and other institutions where I tanght), but this period [of time] made me dive into the deep end and try them [the online tools] out, which never happened before" (e-mail 37, authors' translation). However, the many misconceptions found in the content analysis (referred to in the pedagogy and tools theme) regarding online teaching and learning pedagogical and technological concepts can be attributed to the lack of training and experience.

\section{FACTORS ASSOCIATED WITH FACULTY AND STUDENTS}

The content analysis revealed two main recuring themes associated with the faculty and students (from the faculty point of view): Convenience and Ethical issues.

\section{Convenience}

Convenience can be defined as benefits and ease gained relating to online courses. We investigated faculty's perceptions of convenience related to the synchronous online course (for the faculty and for the students). We identified five aspects related to convenience (or lack of it): Load, Technological issues, Accessibility, Physical environment and Time. 
Faculty reported (five mentions) tiredness due to number of courses online, visual load and fatigue (coined as ZOOM fatigue).

"The phenomenon of zoom fatigue described probably stems from the transformation of all our professional and personal lives into distant interaction with the combination of stress. This creates an emotional and cognitive load which makes it difficult for both us lecturers and of course our students." (e-mail 11, authors' translation)

The aspect of multitasking was mentioned (by two) as one of the reasons for the fatigue.

"A possible cause of this exhaustion is the fact that I need to simultaneously concentrate on teaching, operate a computer, iPad, headphones, operate technical faults (there are quite a few unfortunately) and while also responding to the chat, enter students from the waiting room, pay attention if a student raised a band to ask a question, and answer the students' questions. The lesson ends with a sigh of relief, a cup of coffee and an Advil pill." (e-mail 13, authors' translation)

From the same excerpt (e-mail 13) it is clear that dealing with technological issues before, during, and after the class is an aspect that influence the convenience of the faculty (five mentions).

Regarding the accessibility aspect identified, five out of eight mentions were positive, referring to the flexibility in space and time in information access("the ZOOM added another teaching space with great and useful degrees of freedom when it comes to schedules and meetings beyond the built-in hours system," e-mail 21, authors' translation), the ease to add guest lecturers to the course ("the use of ZOOM allowed me to easily recruit executives from the field of marketing and service as guest lecturers in the courses I teach," e-mail 30, authors' translation), and being able to access information 24/7 (the recordings of the lessons) ("beyond that, the possibility of recording the lessons and uploading the recording to the [course's] site is also an excellent advantage for both students and the lecturer, which can clear questions in the future," e-mail 16, authors' translation).

The three negative mentions referred to specific population of students who need the lesson to be more suited and accessible for them.

"I'm] including in this group not only those with learning disabilities, and attention and concentration disorders, but also those whose mother tongue is different, sitting in classes is not easy for them. ... [so] what is the conclusion from all this? That we can and should look at diversity among students in terms of needs, limitations and difficulties and perhaps aim for a future where we can offer our lessons, accessible in more than one way." (e-mail 37, authors' translation)

The physical environment aspect had seven mentions discussing how the physical conditions support (or not) the online teaching and learning. Some students did not or could not prepare a suitable working/learning environment that would support their learning.

"From my conversations with students and student representatives it appears that for many students the ZOOM lessons are a disaster. The conditions at home are not always suitable for learning. Even so, there are many distractions (e-mails, Whats App, phones, etc.) that many students and especially those with ADHD - have a very hard time dealing with. On the other hand, physical sitting in a classroom creates a learning environment that largely neutralizes background stimuli and encourages learning." (e-mail 34, authors' translation)

Some mentioned the transportation issues and the advantage of not having to stand in traffic: "The advantage for everyone [faculty and students] is the convenience of not leaving home in regarding the lack of having to stand in traffic jams on the way to and from the institution" (e-mail 4, authors' translation).

The issue of private and quiet location was discussed:

"The main advantages mentioned were the convenience of learning from a private environment (and true, there are those who have had it very inconvenient or alternatively impossible...); the possibility to register for 
a course that is not given on days when the students come to study physically at the institution.... Some students have explicitly said that they attend more [online] than they would have if the course had taken place in the [actual] classroom." (e-mail 9, authors' translation)

Technological issues were mentioned four times only. The technological issues did not revolve around malfunctions or lack of knowledge on how to operate the technology but rather on the infrastructure required (e.g., cameras, recordings and so on)

"At our school, all the lessons are recorded. Downloading time [of the recording] to the personal computer and [then] uploading the lesson to the LMS also takes hours after the lesson, which is very frustrating." (email 12, authors' translation)

And last but not least, I have some students who throughout the period appear in every class or session but do not open cameras. Some claimed they had no cameras, that the camera was not working. (e-mail 22, authors' translation)

The time aspect is mentioned in conjunction with the physical environment. In addition to the teaching and learning from home (whether it's a suited for working or learning environment) all 7 mentions agreed that time saving it's an important advantage for both faculty and students.

"Can add and say that the format of personal guidance (for example in seminars) works very successfully in zoom and allows short sessions of about 20 minutes with each of the students individually. This is an excellent substitute for college meetings that students are not always in a burry to get to, because getting there for a 20-minute meeting sometimes requires too much time back and forth." (e-mail 22, authors' translation)

"The transport factor - time, uncertainty and the unpleasant experience in the roads that make it up - are very significant." (e-mail 31, authors' translation)

\section{Ethical issues}

We identified two aspects related to Ethical issues: Copyrights and Privacy. The use of copyrights as a tool for saving creative work and the expression of ideas is gaining an important aspect of intellectual property in higher education institutions especially in the era of online education. The mention regarding copyrights addressed the issue of the recording of the lessons and the concern that it will be circulating outside of the institution. One faculty concluded that: "Addressing issues of privacy, copyright and other legal aspects, which are not always high enough in our priorities, although it is essential that they be there" (e-mail 37, authors' translation).

The ethical issues were mentioned very little throughout the e-mail thread but when mentioned, they raised important point of view. Privacy was mentioned twice in regard to both faculty and students.

"Zoom has also recently come under significant scrutiny due to invasion of privacy and security issues. In addition, distance learning forces us to conduct a lesson while penetrating the private spaces of all of us [faculty and students] using cameras and microphones. Beyond the potential for invasion of privacy, this blurring between the private and the public forces an intimacy that is not always appropriate, in my opinion, for a class in academia." (e-mail 23, authors' translation)

\section{Insights}

Twenty-five mentions were made regarding how the faculty see the future of teaching and learning and how they will utilize online teaching and learning un the future. One faculty member summarized the general set of minds:

"Realizing that even if we are happily returning to face-to-face teaching, we have learned some new things about this situation that we are involved in so many hours a week, we have been given some new perspectives, and perhaps even some new tools (conceptual and practical) that changes how we will enter classes in the future, different from what it has been so far. What is the conclusion from all this? That we can and should look at the differences among students in terms of needs, limitations and difficulties and perhaps aim for a 
future where we can teach our lessons and / or learning the student involve in, accessible in more than one way, in more than one environment. The world of education is talking more and more about "personalized teaching" and maybe we can and should think about it too. Why not try to build a chat option for students even in a regular class?" (e-mail 37 , authors' translation)

Most of the faculty are very eager to return to face-to-face teaching, though most also agreed that they should think how to incorporate the new tools the methodologies they experienced in the future.

\section{FACTORS ASSOCIATED WITH STUDENTS}

The content analysis revealed four main recuring themes associated with the students (from the faculty point of view): Attendance, Responses, Convenience and Ethical issues. The two joint themes, Convenience and Ethical issues, were presented earlier.

\section{Attendance}

We identified two aspects related to Attendance: Presence and participation, and Cameras and Eye contact.

Fourteen mentions directly discussed the presence and participation of students during the lessons, eight of them in negative aspects. Although most mentions reported on high attendance rate, faculty reported a significant drop in active participation in the lesson compared to face-to-face: "Students participate and answer my questions and also ask questions, but fewer students participate and ask than in [face-toface] class" (e-mail 1, authors' translation) and 'In terms of attending lessons, the same students participate and give the lecturer a feeling that he/ she is not alone in the class, but the vast majority of students do not participate" (email 16, authors' translation).

Only few (four) were positive and wrote that they do not see a difference in students' participation between two modalities of teaching.

The aspect of cameras and eye contact got nine mentions, all of them negative. Students tend to not turn on the cameras and thus not allowing the faculty to see them:

"The downside is that it is impossible to look students in the eye and see the understanding or misunderstanding, the interest or alternatively the boredom, and sometimes even the spark that comes up when they understand something that was not clear to them before." (e-mail 2, authors' translation)

"Some students like to turn off the video - and some students enjoy seeing a reflection of themselves. This is interesting in itself. Yes. The responsive facial expressions are missing but it is better than I feared." (e-mail 27, authors' translation)

\section{Responses}

We identified two aspects related to Responses: Attitude change and Social issues.

The attitude change of the students after two months learning via ZOOM got nine mentions. Five mentions were positive and four negatives. The positive ones mentioned the structure, flexibility, and convenience:

"One of the responses I get from a lot of our male and female students is that the fact that they were required to 'appear' in a zoom every week allowed them to maintain a frame during a confusing and uncertain period and even progress on tasks more than they would in normal times." (e-mail 22, authors' translation)

In contrary, the negative ones mentioned the fatigue and spending hours in front of the computer: 
"This week I decided to ask my students in all three classes, and they noted that the zoom is just not good for them: the hours in front of the computer, the disconnections that are in their networks, the writing in front of the screen and more." (e-mail 22, authors' translation)

The social aspect also got nine responses, all negative. The faculty is emphasizing the lack of social interaction between students and students and faculty and students in and out of the classrooms:

"The warm bond with the students is formed much more slowly, and it is not certain that it will reach the same level as in a regular semester" (e-mail 22, authors' translation).

\section{DISCUSSION}

With the outbreak of the global COVID-19 pandemic, many people found themselves in lockdowns, working and studying from home (MacKenzie, 2020). Faculty members were required to transform immediately from face-to-face teaching to synchronous online teaching, and distance teaching has become the main method of teaching. Most faculty were not prepared or trained for this massive adaption.

Dietrich et al. (2020) suggests that teachers recognize that they have learned more about distance education in the early two months of the pandemic than in the past ten years, and this was the result of their constant commitment and dedication to education during this crisis. The study findings created a meaningful understanding of the experiences of higher education faculty regarding the immediate and massive transformation from face-to-face teaching to synchronous online teaching during a crisis (COVID-19 pandemic). The experiences shared by the faculty in an e-mail thread provided insights for teaching and learning beyond the immediate crisis. The findings presented according to the conceptual framework and themes supported the current study and provided first-person accounts of faculty's experiences using synchronous (ZOOM) online courses in higher education from the faculty's point of view.

\section{FACTORS ASSOCIATED WITH FACULTY}

We identified two main themes associated with the faculty: Pedagogy and tools and Resources. Pedagogy is an important aspect of teaching and learning in general and online learning in particular. Faculty work intensively to adapt their planned learning activities to fit distance education. Findings show that the faculty regards synchronous online teaching as less suited for their pedagogical needs and understanding mainly in large classes (number of students). Synchronous teaching is seen as a tool for small class discussions and mentoring. Faculty use digital tools mostly within the ZOOM environment thus are limited to ZOOM's local capabilities. Faculty attitudes on the importance of online teaching competency and their perception of their ability play a major role in how faculty approach online teaching goals, tasks, and challenges (Martin et al., 2019). Three main aspects were identified regarding Resources: efforts, costs (and savings), and professional development (training).

The efforts aspect raised issues mainly related to the aspects of time needed for the faculty to invest in such a transformation and the institution to fund those action (including the faculty's efforts). Instructors value the personal and professional rewards that resulted from their online teaching, such as flexible schedules and professional development opportunities (Wingo et al., 2017). Although only one explicit mention was made about professional development (training) and experience, we assume lack of training and experience from the many misconceptions found in the content analysis regarding online teaching and learning pedagogical and technological concepts. As others noted, one of the challenges is the provision of suitable and effective training support to faculty (Rasheed et al., 2020). Wingo et al. (2017) explored the literature for faculty perceptions about teaching online and found that many of the studies showed that instructors adapted well to the online environment as they gained more experience. Faculty who was teaching online were gratified when institutions provided mentoring, training, support, and recognition of their success. Researchers have recommended the 
need for faculty training for online teaching focusing on methodologies and facilitation (e.g., Moskal et al., 2015).

\section{FACTORS ASSOCIATED WITH FACULTY AND STUDENTS}

We identified two main recuring themes associated with the faculty and students (from the faculty point of view): Convenience and Ethical issues. Convenience can be defined as benefits and ease gained relating to online courses. We investigated faculty's perceptions of convenience related to the synchronous online course (for the faculty and for the students). We identified five aspects related to convenience (or lack of it): Load, Technological issues, Accessibility, Physical environment, and Time.

Faculty reported tiredness, visual load, and fatigue (coined as ZOOM fatigue), with the explanation of multitasking. Regarding the accessibility aspect, faculty referred to the flexibility in space and time in information access with the emphasis of the need to make the lessons more accessible to specific population of students. In some cases, the physical environment conditions supported the online teaching and learning, and, in some cases, it did not. Some students did not or could not prepare a suitable working/learning environment that would support their learning.

Technologically wise, it was surprising to find that the discussion did not revolve around lack of technological knowledge or malfunction of technology but the lack of sufficient infrastructure and only by four. Past studies found that, whether faculty were already teaching online or not, faculty's perceptions about the user-friendliness of technology and their own skills in mastering LMS and other tools played a role in their satisfaction with online teaching and learning (Wingo et al., 2017). We can assume that by not mentioning the technology issues and giving it a weight in the discussion, the faculty are starting to get familiar with the technological environment and feel more comfortable.

Harry et al. (2010) defined benefit convenience for online courses as the time and effort required for the successful completion of an online course. They also argue that greater benefit convenience results in increased student perceptions of learning and that convenience is an important determinant of student satisfaction and perceived value from a course. Online courses need to be perceived as convenient, but also provide interaction with other students and impactful faculty, both of which significantly associate with students' course satisfaction and perceived learning (Sanford et al., 2017).

We identified two aspects related to Ethical issues: Copyrights and Privacy. The use of copyrights as a tool for saving creative work and "the expression of ideas" (Depoorter, 2004, p. 53) is gaining momentum, as the rise of ICT in recent years has led to a permanent increasing relevance of such protection (Burrone, 2005). Faculty agreed that the topics of copyrights and legal issues should be properly addressed. The ethical issues were mentioned very little throughout the e-mail thread but, when mentioned, they raised important points of view. Privacy was discussed in the context of mixing the public with the private space and the confusion it creates.

\section{FACTORS ASSOCIATED WITH STUDENTS}

Although most mentions reported on high attendance rate in the synchronous online lessons, faculty reported a significant drop in active participation in the lessons compared to face-to-face ones. It seems that students are lacking the motivation to be an active learner and prefer to be a spectator. It coincides with the emphasize that there is a lack of social interaction between students and students and faculty and students in and out of the classrooms.

The reports on low active participation rate coincide with the phenomena of refusing to turn on the cameras for various reasons including the privacy aspect. All these reasons are legitimate, although most of the systems used to facilitate distance learning have an option to define any picture as a virtual background and thus eliminate the privacy problem (Henry \& Shellenbarger, 2020). Moreover, students do not realize that their decision to not join in on the distance-learning class through their 
cameras affects their psychological engagement in the virtual classroom, and this lack of engagement reduces their interactive learning (Krystalli, 2020; Neuwirth et al., 2020).

\section{INSIGHTS}

Most of the faculty are very eager to return to face-to-face teaching, though most also agreed that they should think about how to incorporate the new tools and the methodologies they experienced in the future and change their pedagogical approaches. As one faculty member described the transformation: "What we are doing right now is not online teaching but (most of the time and certainly in large courses) duplicating a traditional course through zooming. It is a format that combines the less successful aspects of traditional teaching and of online teaching." We can observe a positive attitude towards online teaching and learning and as Clay (1999) found, factors that influence faculty's positive attitudes toward teaching online are prior experience teaching online, which they got (even if not by option).

A change in pedagogical approach is needed and for that we need to develop a large-scale professional development scheme, which includes the development of competencies and lets the faculty gain actual experience in designing and teaching online courses in various environments and modalities.

Natural disasters can stimulate motivation for the adoption of innovative ICT and e-learning tools (Tull et al., 2017). In a similar crisis situation in New-Zealand in 2011, Ayebi-Arthur (2017) found in a case study that the lack of an explicit e-learning strategy influenced the college to develop a collegespecific e-learning plan and that complemented the incorporation of e-learning for the first time in the university's teaching and learning strategy in 2013.

\section{CONCLUSIONS}

The COVID-19 pandemic demanded an immediate and massive adaptation of higher education to distance learning. Faculty had to transform from face-to-face to distance teaching, with insufficient pedagogical and technological knowledge and resources. This study aims to capture higher education faculty experiences in the very early stages of the crisis-prompted transition into synchronous distance education in order to obtain a broader view on the faculty's perspectives (benefits, challenges, and insights) on distance teaching through synchronous online environments. The study presented a conceptual model based on qualitative case study methodology. Findings identified seven main recuring themes regarding the experience of teaching in the first two months of the higher education lockdown. Two main focal points, students and teachers were encountered. Three main recurring themes were identified associated with both students and teachers: Convenience, Ethical Issues, and Insights for the future. Two themes were identified associated with faculty: Pedagogy and Tools, and Resources. In addition, two themes were identified for students: Attendance and Responses. Each of the themes was decomposed into several aspects. The findings contribute to the understanding the benefits and challenges of distance learning from the faculty perspectives in order to implement better distance learning strategies. In addition, the findings contribute to the knowledge domain of implementation of immediate and massive online teaching and learning.

\section{RECOMMENDATION}

Higher education institutions and stakeholders should build a campus wide e-learning agenda including appropriate infrastructure and professional development for the future. Moreover, nowadays, after the initial shock has passed higher education institutions, administrators, and faculty need to reconsider how they might better invest time and resources in e-leaning methodologies and infrastructure and course design (Rapanta et al., 2020). We reinvoke earlier callings for higher education institutions preparedness plans and change to a hybrid teaching. 
Based on the findings of this study and the discourse created by this tread, the institution, as a first step, decided to organize a four-day online education conference aiming at the professional development of its academic staff (faculty) related to pedagogy and technology specifically in synchronous learning environment. In addition, a preparation for a long-term campus wide e-learning strategy has started, resulting in the preparation of an initial policy paper submitted to the Council of Higher Education.

\section{LIMITATIONS}

Several limitations must be considered when interpreting the results of this study. This study employed a case study qualitative methodology, and the data collection was limited to the 35 faculty members in one higher education institution who decided to share their experience in an e-mail thread. So, it might not be representative of all faculty and higher education institutions. Moreover, this study reflects the earliest phase of the transition (two months in), and as such it does not capture how things developed later on.

\section{FUTURE STUDY}

The impact and influence of each of the components of the conceptual model should be further researched and measured using quantitative methodologies. Due to the fact that this study reflects the earliest phase of the transition, the later stages of the implementation should be followed up with future studies.

\section{REFERENCES}

Allen, I. E., \& Seaman, J. (2010). Learning on demand: Online education in the United States. Sloan Consortium.

Ayebi-Arthur, K. (2017). E-learning, resilience and change in higher education: Helping a university cope after a natural disaster. E-Learning and Digital Media, 14(5), 259-274. https://doi.org/10.1177/2042753017751712

Barrett, B. (2010). Virtual teaching and strategies: Transitioning from teaching traditional classes to online classes. Contemporary Issues in Education Research 3, 17-20. https://doi.org/10.19030/cier.v3i12.919

Basilaia, G., \& Kvavadze, D. (2020). Transition to online education in schools during a SARS-CoV-2 coronavirus (COVID-19) pandemic in Georgia. Pedagogical Research, 5(4). https://doi.org/10.29333/pr/7937

Betts, K., \& Heaston, A. (2014). Build it but will they teach? Strategies for increasing faculty participation and retention in online and blended education. Online Journal of Distance Learning Administration, 17(2).

Bolliger, D. U., \& Wasilik, O. (2009). Factors influencing faculty satisfaction with online teaching and learning in higher education. Distance Education, 30(1), 103-116. https://doi.org/10.1080/01587910902845949

Burrone, E. (2005). Intellectual property rights and innovation in SMEs in OECD countries. Journal of Intellectual Property Rights, 10(1), 34-43.

Carril, P. C. M., Sanmamed, M. G., \& Sellés, N. H. (2013). Pedagogical roles and competencies of university teachers practicing in the e-learning environment. The International Review of Research in Open and Distributed Learning, 14(3), 462-487. https://doi.org/10.19173/irrodl.v14i3.1477

Castelli, F. R., \& Sarvary, M. A. (2021). Why students do not turn on their video cameras during online classes and an equitable and inclusive plan to encourage them to do so. Ecology and Evolution, 11(8), 3565-3576. https://doi.org/10.1002/ece3.7123

Clay, M. (1999). Faculty attitudes toward distance education at the State University of West Georgia. University of West Georgia Distance Learning Report. http://www.westga.edu/ distance/attitudes.html

Depoorter, B. (2004). The several lives of Mickey Mouse: The expending boundaries of intellectual property law. Virginia Journal of Law \& Technology, 9(4), 1-68.

Dhawan, S. (2020). Online learning: A panacea in the time of COVID-19 crisis. Journal of Educational Technology Systems, 49(1), 5-22. https://doi.org/10.1177/0047239520934018 
Zooming?! - Higher Education Faculty Perspectives

Dietrich, N., Kentheswaran, K., Ahmadi, A., Teychené, J., Bessière, Y., Alfenore, S., Laborie, S., Bastoul, D., Loubière, K., Guigui, C., Sperandio, M., Barna, L., Paul, E., Cabassud, C., Liné, A., \& Hébrard, G. (2020). Attempts, successes, and failures of distance learning in the time of COVID-19. Journal of Chemical Education, 97(9), 2448-2457. https://doi.org/10.1021/acs.jchemed.0c00717

Emo, W. (2015). Teachers' motivations for initiating innovations. Journal of Educational Change, 16(2), 171-195. https://doi.org/10.1007/s10833-015-9243-7

Gafni, R., Shaul, L. \& Tauber, D. (2011). E-learning diurnal time patterns in the navy. Navigating Informational Challenge. Issues in Informing Science and Information Technology (IISIT), 8, 377-393. https://doi.org/10.28945/1425

Garrison, D. R., \& Kanuka, H. (2004). Blended learning: Uncovering its transformative potential in higher education. The Internet and Higher Education, 7(2), 95-105. https://doi.org/10.1016/j.iheduc.2004.02.001

Gaskell, G. (2000). Individual and group interviewing. In M. W. Bauer \& G. Gaskell (Eds.), Qualitative researching with text, image and sound: A practical handbook (pp. 38-56). Sage. https://doi.org/10.4135/9781849209731

Greener, S. (2021). Exploring remote distance learning: What is it and should we keep it? Interactive Learning Environments, 29(1), 1-2. https://doi.org/10.1080/10494820.2021.1848506

Harry, J. R., Collier, J. E., Ponder, N., \& White, L.A. (2010). It isn't easy, but is it convenient? An investigation of online education convenience. Society for Marketing Advances Proceedings, 138-139.

Heaton, M. (2020). Academics must not rage against 'death by blank screen'. Times Higher Education. https://www.timeshighereducation.com/blog/academics-must-not-rage-against-death-blank$\underline{\text { screen }}$

Henry, A., \& Shellenbarger, T. (2020). To Zoom or not to Zoom? Choosing a videoconferencing platform. Nurse Author \& Editor, 30(4), 3. https://doi.org/10.1111/nae2.9

Hoyt, J. E., \& Oviatt, D. (2013). Governance, faculty incentives, and course ownership in online education at doctorate-granting universities. American Journal of Distance Education 27, 165-178. https://doi.org/10.1080/08923647.2013.805554

Ko, S., \& Rossen, S. (2017). Teacbing online: A practical guide. Routledge.

Kozma, R. (2000). Reflections on the state of educational technology - Research and development. Educational Technology Research and Development 48(1), 5-15. https://doi.org/10.1007/bf02313481

Krystalli, P. (2020). Undergraduate students' perceptions of virtual teaching. European Journal of Social Science Education and Research, 7(3), 121-130.

Kurtz, G., Teeni, D., Mevarech, Z., \& Neuthal, T. (2006). The experience of implementing instructional technology in Israel higher education. Perspectives on higher education in the digital age. Nova Science Publishers.

Kyei-Blankson, L., \& Keengwe, J. (2011). Faculty-faculty interactions in online learning environments. International Journal of Information and Communication Technology Education 7, 25-33. https://doi.org/10.4018/jicte.2011070103

Li, C., \& Irby, B. (2008). An overview of online education: Attractiveness, benefits, challenges, concerns, and recommendations. College Student Journal, 42, 449-458.

MacKenzie, D. (2020). Covid-19 goes global. New Scientist, 245(3271), 7. https://doi.org/10.1016/s0262$\underline{4079(20) 30424-3}$

Marinoni, G., Van't Land, H., \& Jensen, T. (2020). The impact of Covid-19 on higher education around the world. LAU Global Survey Report.

Martin, F., Budhrani, K., \& Wang, C. (2019). Examining faculty perception of their readiness to teach online. Online Learning, 23(3), 97-119. https://doi.org/10.24059/olj.v23i3.1555

McBrien, J. L., Cheng, R., \& Jones, P. (2009). Virtual spaces: Employing a synchronous online classroom to facilitate student engagement in online learning. The International Review of Research in Open and Distributed Learning, 10(3). https://doi.org/10.19173/irrodl.v10i3.605 
McQuiggan, C. (2012). Faculty development for online teaching as a catalyst for change. Journal of Asynchronous Learning Networks, 16(2), 27-61.

Meeter, M., Bele, T., Den Hartogh, C., Bakker, T., de Vries, R. E., \& Plak, S. (2020, October 11). College students' motivation and study results after COVID-19 stay-at-home orders. https://doi.org/10.31234/osf.io/kn6v9

Miles, M. B., \& Huberman, A. M. (1994). Qualitative data analysis: An expanded sourcebook (2nd ed.). Sage Publications.

Moorhouse, B. L. (2020). Adaptations to a face-to-face initial teacher education course 'forced' online due to the COVID-19 pandemic. Journal of Education for Teaching, 46(4), 609-611. https://doi.org/10.1080/02607476.2020.1755205

Moskal, P., Thompson, K., \& Futch, L. (2015). Enrollment, engagement, and satisfaction in the BlendKit faculty development open, online course. Online Learning, 19(4), 1-12. https://doi.org/10.24059/olj.v19i4.555

Neuwirth, L. S., Jović, S., \& Mukherji, B. R. (2020). Reimagining higher education during and post-COVID-19: Challenges and opportunities. Journal of Adult and Continuing Education. https://doi.org/10.1177/1477971420947738

Potter, J., \& Wetherell, M. (1987). Discourse and social psychology: Beyond attitudes and behaviour. Sage Publications.

Rapanta, C., Botturi, L., Goodyear, P., Guàrdia, L., \& Koole, M. (2020). Online university teaching during and after the Covid-19 crisis: Refocusing teacher presence and learning activity. Postdigital Science and Education, 2(3), 923-945. https://doi.org/10.1007/s42438-020-00155-y

Rasheed, R. A., Kamsin, A., \& Abdullah, N. A. (2020). Challenges in the online component of blended learning: A systematic review. Computers \& Education, 144, 103701. https://doi.org/10.1016/i.compedu.2019.103701

Reeves, T. C., \& Reeves, P. M. (2012). Designing online and blended learning. In L. Hunt \& D. Chalmers (Eds.), University teaching in focus: A learning-centered approach (pp. 112-127). Routledge. https://doi.org/10.4324/9780203079690-7

Reich, J., Buttimer, C. J., Coleman, D., Colwell, R., Faruqi, F., \& Larke, L. R. (2020). What's lost, what's left, what's next: Lessons learned from the lived experiences of teachers during the pandemic. https://doi.org/10.35542/osf.io/8exp9

Sanford, D., Ross, D., Rosenbloom, A., \& Singer, D. (2017). Course convenience, perceived learning, and course satisfaction across course formats. E-Journal of Business Education and Scholarship of Teaching, 11(1), 69-84.

Seaman, J. E., Allen, I. E., \& Seaman, J. (2018). Grade increase: Tracking distance education in the United States. Babson Survey Research Group. https://bayviewanalytics.com/reports/gradeincrease.pdf

Shea, P. (2007). Bridges and barriers to teaching online college courses: A study of experienced online faculty in thirty-six colleges. Journal of Asynchronous Learning Networks, 11(2). https://doi.org/10.24059/oli.v11i2.1728

Singh, V., \& Thurman, A. (2019). How many ways can we define online learning? A systematic literature review of definitions of online learning (1988-2018). American Journal of Distance Education, 33(4), 289-306. https://doi.org/10.1080/08923647.2019.1663082

Soffer, T., \& Cohen, A. (2019). Students' engagement characteristics predict success and completion of online courses. Journal of Computer Assisted Learning, 35(3), 378-389. https://doi.org/10.1111/jcal.12340

Stake, R. E. (1995). The art of case study research. SAGE Publications.

Tareen, H., \& Haand, M. T. (2020). A case study of UiTM post-graduate students' perceptions on online learning: Benefits \& challenges. International Journal of Advanced Research and Publications, 4(6), 86-94.

Thomas, G. (2011). A typology for the case study in social science following a review of definition, discourse, and structure. Qualitative Inquiry, 17(6), 511-521.

Tull, S. P. C., Dabner, N., \& Ayebi-Arthur, K. (2017). Social media and e-learning in response to seismic events: Resilient practices. Journal of Open, Flexible and Distance Learning, 21(1), 63-76. 
Vang, K., Martin, F., \& Wang, C. (2020). Examining community college faculty perceptions of their preparedness to teach online. Journal of Applied Research in the Community College, 27(1), 45-63.

Varvel, V. E. (2007). Master online teacher competencies. Online Journal of Distance Learning Administration, 10(1), $1-41$.

UNESCO. (2020). COVID-19 educational disruption and response. https://en.unesco.org/themes/educationemergencies/coronavirus-school-closures.

Walther, J., Sochacka, N. W., \& Kellam, N. N. (2013). Quality in interpretive engineering education research: Reflections on an example study. Journal of Engineering Education, 102(4), 626-659. https://doi.org/10.1002/jee.20029

Wingo, N. P., Ivankova, N. V., \& Moss, J. A. (2017). Faculty perceptions about teaching online: Exploring the literature using the technology acceptance model as an organizing framework. Online Learning, 21(1), 15-35. https://doi.org/10.24059/olj.v21i1.761

Wray, M., Lowenthal, P. R., Bates, B., \& Stevens, E. (2008). Investigating perceptions of teaching online \& f2f. Academic Exchange Quarterly, 12(4), 243-248.

Yang, Z., \& Liu, Q. (2007). Research and development of web-based virtual online classroom. Computers \& Education, 48(2), 171-184. https://doi.org/10.1016/i.compedu.2004.12.007

Yazan, B. (2015). Three approaches to case study methods in education: Yin, Merriam, and Stake. The Qualitative Report, 20(2), 134-152. https://doi.org/10.46743/2160-3715/2015.2102

Yin, R. K. (2014). Case study research: Design and methods. SAGE Publications.

\section{AUTHORS}

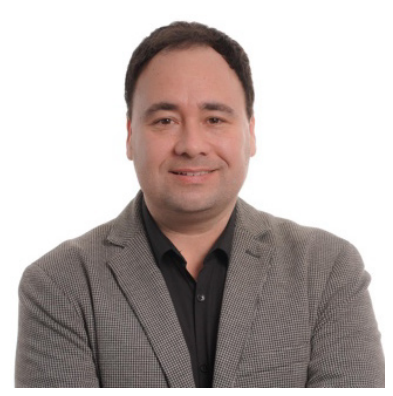

Moshe Leiba is an assistant professor at the school of Information Systems and heads the Digital Learning Project at The Academic College of Tel Aviv Yaffo. He also acts as Chief Pedagogical Officer of World ORT Kadima Mada. Moshe holds a B.Sc in Electrical Engineering, a Teaching Certificate, a MA (Magna cum Laude) and a PhD focusing on Digital Education from Tel Aviv University. Moshe participated in several European ICT research programs (FP7, FP6, Erasmus) as a researcher and has experience as a policy maker in formal education systems at governmental and municipal levels.

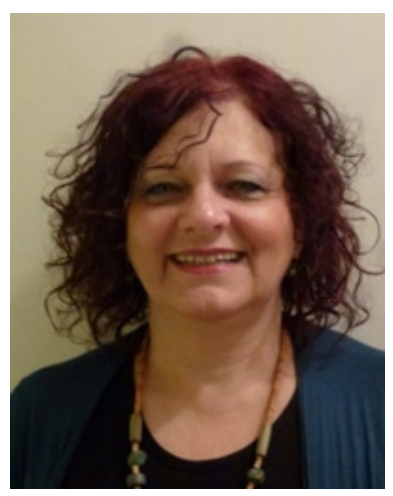

Ruti Gafni is an Associate Professor, and Dean of the School of Information Systems at The Academic College of Tel Aviv Yaffo. She holds a $\mathrm{PhD}$ from Bar-Ilan University, Israel (in the Business Administration School), focusing on Information Systems, an M.Sc. from Tel Aviv University and a BA (Cum Laude) in Economics and Computer Science from Bar-Ilan University. She has more than 40 years of practical experience as Project Manager and Analyst of information systems. 